\title{
Applying the Investment Multiplier to Identify Key Points of Economic Growth
}

\author{
Mikhail Evgenievich Kosov ${ }^{1,2 *} \mathbb{0}$, Vladimir Vladimirovich Eremin ${ }^{2}$, \\ Sergey Alekseevich Pobyvaev ${ }^{2}$, Tural Sokhbat Ogly Gaibov ${ }^{2}$ \\ ${ }^{I}$ Department of Finance and Prices, Plekhanov Russian University of Economic, Moscow, Russia. \\ ${ }^{2}$ Financial University under the Government of the Russian Federation, Moscow, Russia.
}

\begin{abstract}
The crisis phenomena irregularity due to the COVID-19 pandemic requires new, to a certain extent, non-routine tools for their settlement, namely the action effect enhancers of the state and private investors to develop the economy in conditions of shrinking volumes of available financial resources. The paper proposes the Investment Multiplier (IM) as such a tool. The author's model was generated based on a detailed description of developing multiplier processes to analyze its action. The study aims to estimate the IM values of the economies of Kurgan, Sverdlovsk, and Chelyabinsk, the most industrially developed Russian regions, and identify the main points of their economic growth. The key research method was regression analysis. The present study establishes interconnectivity between marginal propensity and savings, marginal propensity and imports, marginal tax rate, and investment accelerator, and their influence on the regional multiplier. From a position of investment multiplier, the authors try to narrow the research gap in how investment policies influence the economic growth of the Russian regions. The study results determine IM values for the analyzed regions, identifying their differences and reasons. The key points of economic growth in these regions were identified. The scientific novelty involves applying changes in regional multiplier processes' dynamics to determine the key development points. The practical significance is that the IM value is an analytical tool that will identify existing key points of regional economic development and, by managing the IM value, create new points for investments with a large-scale multiplier effect, thus developing the regional economy.
\end{abstract}

\author{
Keywords: \\ Multiplier; \\ Investment; \\ Accelerator; \\ Region; \\ Multiplier Effect; \\ Economy. \\ Article History: \\ $\begin{array}{llll}\text { Received: } & 26 & \text { October } & 2021 \\ \text { Revised: } & 20 & \text { December } & 2021 \\ \text { Accepted: } & 08 & \text { January } & 2022 \\ \text { Available online: } & 27 & \text { February } & 2022\end{array}$
}

\section{1- Introduction}

Today's crises (including the crisis caused by the COVID-19 pandemic) are spreading at a fairly high rate in the economy, slowing down an overwhelming number of economic sectors. Federal and regional governments must therefore respond quickly and effectively to changing economic dynamics with limited funding. Many private investors have suffered losses and, due to unabated risks, are often not ready to invest their limited funds in the anti-crisis development of the economy. According to the results of 2020, the above-mentioned factors caused the budget deficit in 58 of 85 regions of the Russian Federation [1]. The overall deficit of the Russian regional budgets in 2020 reached 762.2 billion rubles, or $5 \%$ of the total revenues of the regional budgets.

The new, more dynamic, and comprehensive crisis, the limited use of traditional tools of monetary and fiscal policy, and all these trends determine the need to find and use new tools to stimulate the economic development of the country's regions. In our view, IM can be such a tool. Its influence strengthens the actions of public and private investors aimed at

*CONTACT: mikhail_kosov_hse@mail.ru

DOI: http://dx.doi.org/10.28991/ESJ-2022-06-02-05

(C) 2022 by the authors. Licensee ESJ, Italy. This is an open access article under the terms and conditions of the Creative Commons Attribution (CC-BY) license (https://creativecommons.org/licenses/by/4.0/). 
developing regional economies because it spreads the initial effect of investment in a particular industry to other industries and regions, often weakly related to the one under development. In this context, the multiplier's use is based on its action as an investment impact enhancer on the economic dynamics and the difference between particular regions' and industries' values of the IMs, helping identify key points in the regional economic development. All of the above makes the present study relevant. The scientific novelty and importance of the present study can be outlined as the formulation of a methodology for applying changes in regional multiplicative processes to identify key points of development. This study aims to estimate the values of the IMs of regional economies (Kurgan, Sverdlovsk, and Chelyabinsk regions as one of Russia's most industrially developed regions) to identify key areas and points of economic growth in the regions in question. Based on the set objective, the following tasks are solved in the work:

- To review the existing approaches to calculating the IM within the domestic and foreign studies.

- To propose an approach to estimating the IM, considering the differences and peculiarities of the investment potential level of the analyzed regions of Russia.

- To determine the main directions of economic development of the regions under consideration using the potential of the multiplier effect.

The methodological scheme of this study is presented in Figure 1.

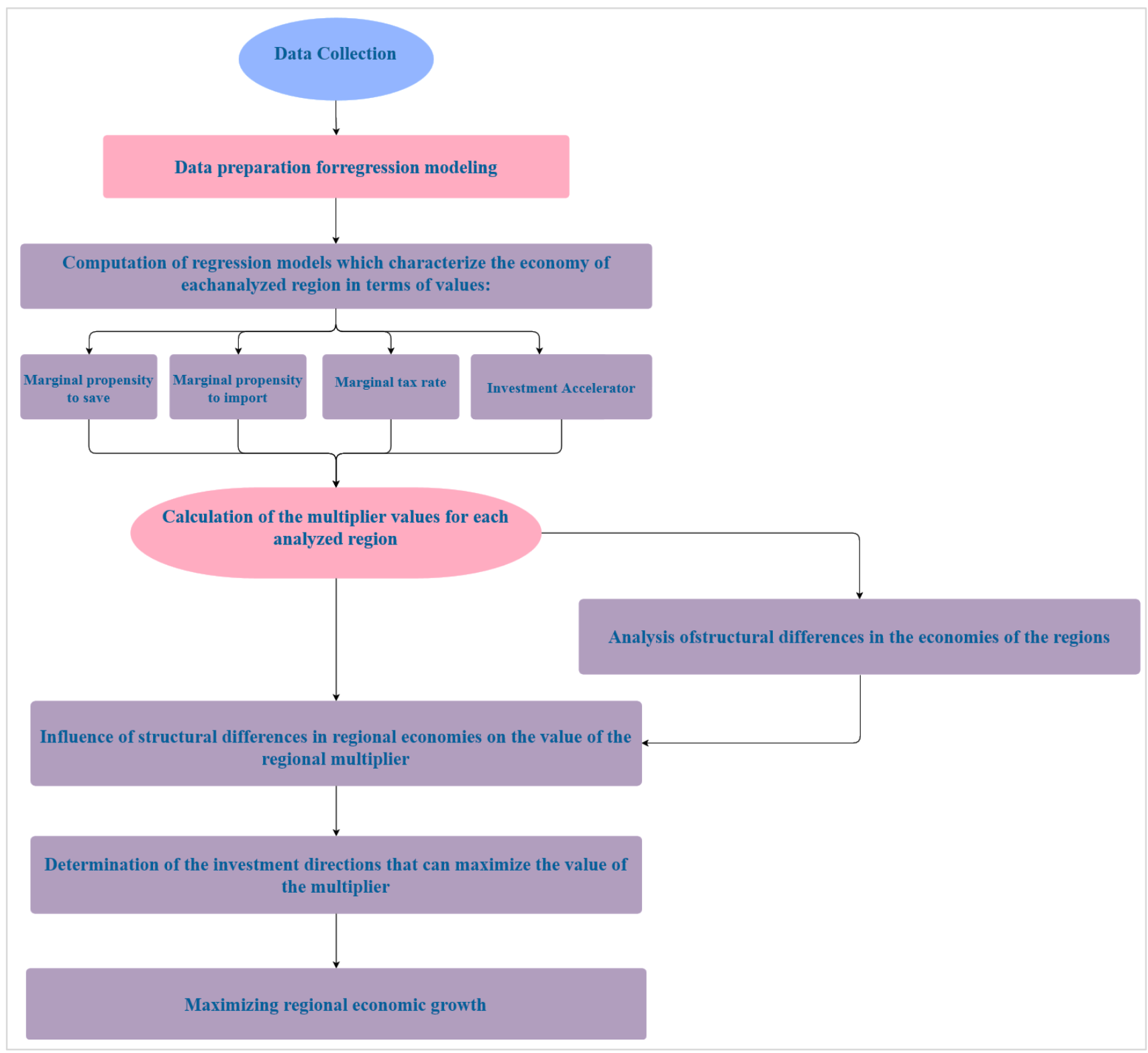

Figure 1. The methodological framework of the study

The structures of this study are as follows: The introduction substantiates the need for an IM and provides a hypothesis, purpose, and objectives of the study. The next section is a literature review, which includes an analysis of foreign and domestic literature, making it possible to analyze the existing methods and approaches to multiplier 
formation. The "Materials and Methods" section proposes and models the author's approach to estimating the multiplier, which is tested in the "Results" section on the example of particular regions of Russia. The "Discussion" section makes it possible to determine whether the results obtained correspond to the study hypotheses. It also gives a summary of the results that came from the study in "Conclusion".

\section{2- Literature Review}

Modern researchers pay attention to the problem of the IM application. The growing attention to this topic is largely due to the impact of the COVID-19 pandemic on the world economy, in which, on the one hand, the decline in economic activity is enhanced by multiplier effects; on the other hand, multiplier effects enhance the recovery of national economies and the world economy as a whole. Quite often, for modeling the multiplier effects, the authors apply the input-output model [2]. In particular, its improved version, Social Accounting Matrices, is used to prove the multiplier enhancement of the negative impact of the COVID-19 pandemic on the macroeconomic system of China in general and the agro-food system of the country in particular [3]. A model like this is used to look at how pandemic containment measures affect the economy of Myanmar [4].

Based on the Input-Output matrix, the authors investigate the negative multiplier effects in the Greek economy caused by the impact of COVID-19 on the country's tourism industry [5] and prove the multiplier effect of employment dynamics in the South African economy [6]. The authors prove positive multiplier effects of transfer payments to households during the coronavirus lockdown in the US economy, pointing out the difference in the volume of multiplier effect depending on whether transfers are conditional or unconditional and their recipients are unemployed or employed [7]. The multiplier effects of productive and non-productive budget expenditures are analyzed [8].

Exploring the multiplier effects by the input-output matrix, the authors supplement it with the interregional product supply block [2, 9], calculate the values of industry multipliers for the Russian economy [6], prove the applicability of government expenses for supporting private demand, forming large-scale multiplier effects [10]. Studies show increasing values of fiscal multipliers and government spending multiplier during economic shocks like COVID-19 or the Great Depression [11], proving the possibility of using multiplier effects as tools to counteract the decline in economic activity caused by the COVID-19 lockdown. Along with Input-Output matrices, the authors actively use regression models to determine the values of the IM (the government spending multiplier, in particular). The result of some such studies indicates higher values of the government spending multiplier in emerging economies [8], which gives an additional impetus to their use as a tool for economic development. At the same time, the authors point out the lower values of Russian sectoral multipliers compared to those in the U.S. [12].

The division of the government spending multiplier into the government IM and the government consumption multiplier helped to reveal a higher value of the latter [13]. Based on econometric models, a positive multiplier effect of budgetary expenditures in one region's economy on the economy of another region is proved [14]. Researchers use such models to determine the points of growth of national economies. In particular, such research was conducted for the Tatarstan economy [15]. Based on regression models, the dependence of regional IMs on the economic structure of Russian regions was established [16], and differences in the multiplier effects of different types of government spending and different types of tax exemptions used to finance them were determined [5, 17].

Researchers point out differences in IM effects' volume in infrastructure depending on the region [18] and investment application industry [19] and the need to activate those sectors of the economy, "The increasing demand for their products has a significant positive impact on the economy" [20]. However, in particular, based on the analysis of data on the U.S. economy over the past 120 years, researchers conclude that the values of the government spending multiplier are resistant to the negative impact of crisis phenomena [21]. Other researchers have concluded that increased government investment has a sustained effect on production level when considering fiscal forecasts in OECD countries for 1970-2016 [22]. It has been proven using real-time forecasts of government consumption and investment that the estimated government IM is close to zero, while the government consumption multiplier is approximately 0.8 . In this regard, financial incentive packages that contain large government investment components may not be as effective in stimulating aggregate demand as is commonly believed [13].

A group of Japanese researchers concluded that government spending impacts consumption and investment. The regional budget multiplier of absorption exceeds 2.0. The absorption by-effect is significant in contrast to the production by-effect [23]. Another study showed that the initial production potential becomes a specific factor determining the right strategic decisions (in terms of scale) and the ability to make comprehensive investments in the modernization of regions, including those financed jointly with investment mechanisms [24]. Using quarterly data from 2000 to 2018, a group of European researchers identified an exogenous increase in government spending based on Cholesky decomposition and calculated impulse response functions based on linear predictions [1]. Research on this topic remains limited in developing countries. However, an article [25] investigates the multiplier effect of local government spending in regions of the Philippines. The local budget multiplier is estimated to be above 1.0 (an increase in local government spending of 1 peso in a region corresponds to an increase in a regional production of 1.2 pesos). 
Another study presents changes in the value of the tax, investment, and export multipliers influenced by the COVID19 pandemic. The present study was built on the theoretical basis of effective demand and found that some countries' multipliers of autonomous expenditures have increased. This increase in their cost has weakened the negative impact of changes in autonomous expenditures on gross domestic product [26]. Another study using real-time forecasts of public consumption and investment of a group of OECD countries concludes that fiscal stimulus packages containing large public investment components may not be as effective for stimulating aggregate demand as commonly believed [27].

The authors analyze the welfare multiplier of public spending and note its crucial dependence on public capital productivity (output elasticity), public capital depreciation rate, and public investment efficiency, defined as the share of public investment expenditures converted into the public capital fund [28].

Using regression modeling methods, the authors consider various options for assessing the multiplicative effects caused by investments in certain sectors of the economy. They conclude that a country's particular industry success should be measured by its share in the gross output of the macro system or value added and the multiplicative effect of investments in the industry on the development of other industries, employment, and the overall national product [29]. Another paper using similar mathematical methods identifies the reserves of economic development of Russia's regions. It ranks the economic activity of the regions by the strength of its influence on the value of the investment multiplier to further manage this value [30].

The literature review revealed some problems that analysts and economists-researchers in this subject area may face. The most significant ones are different ways of calculating multipliers (the chosen multipliers must be calculated equally); another problem in determining the multiplier is the consistency of the numerator and denominator.

The analysis of domestic and foreign studies of the IM concerning this paper also allows us to make two auxiliary hypotheses:

- The IM is the action enhancer of public and private investors on developing the country's economy.

- The multiplier values of particular industries and regions of the Russian Federation are different.

\section{3- Materials and Methods}

The multiplier is a numerical coefficient showing how many units the gross national (regional) product will grow when the volume of investment increases by one unit. Here is a brief and simplified conclusion of the formula for the IM. In a truncated form without considering external relations and allocation of government spending, it looks like:

$$
G R P=C+I
$$

where GRP is the value of the gross regional product for the analyzed period, $C$ is the amount of consumer spending in the region's economy for the analyzed period, and $I$ is the amount of investment expenditures in the region's economy for the analyzed period. Given that the value of the marginal propensity to consume (MPC) is determined by the formula:

$$
M P C=\frac{C}{G R P}
$$

Equation 1 takes the form:

$$
G R P=M P C \times G R P+I
$$

From which follows:

$$
G R P-M P C \times G R P=I \rightarrow G R P \times(1-M P C)=I
$$

Given that MPC shows the number of units spent on consumption per one additional unit of obtained GRP, the multiplier (1-MPC) shows the number of units not spent, i.e., units of outward flows of one kind or another (savings, tax payments, and others) from the consumption process. Based on this, let us denote:

$$
1-M P C=M_{\text {out }}
$$

where $M_{\text {out }}$ is the limit value of outward flows from the analyzed process. Hence:

$$
G R P \times M_{\text {out }}=I
$$

From which:

$$
G R P=\frac{1}{M_{\text {out }}} \times I
$$

where $\frac{1}{M_{\text {out }}}$ is the IM value. By differentiating Equation 7 as $\frac{d y}{d x}$, we obtain:

$$
\frac{d G R P}{d I}=\frac{1}{M_{\text {out }}}
$$


For maximizing the multiplier's action as an enhancer of investors' activity on the economic development, it is necessary to determine the places of this activity application with its help. Two options are possible:

- Identifying regions (and industries within their economies) that have the maximum multiplier effect. Combining these regions and industries will help determine the key points of regional economies, where the investment of resources will maximally spread economic growth to the surrounding industries and regions.

- Determining the reasons for low values of the IM in particular regions and sectors of their economies to develop measures to increase multiplier values and create prerequisites for the formation of new points of growth on the economic map of Russia.

Such an approach makes it possible to transform the IM from an analytical tool into a full-fledged tool of regional economy management. To quickly calculate the value of the IM, we propose using a detailed description of the multiplier process spread to form the multiplier model. This process is triggered by initial investments in the region's economy. Performers of works and product suppliers on the orders of investors receive their investments in the form of their income and (except for savings) spend them on purchasing production factors. The owners of these factors do the same, involving new participants in the multiplier process.

Suppose production factors are purchased outside the region (in the economies of other regions, other countries). In that case, it will reduce the multiplier effect in the economy of the analyzed region, directing the multiplier impulse born in it to developing the economies of other regions. Consequently, the outward flows from the multiplier process are not limited exclusively to savings. It includes outward flows associated with importing products into the region's economy (from other regions and countries) and paying taxes.

Given these outward flows, the initial investment $\left(\mathrm{IN}_{1}\right)$ triggers the first part of the multiplier process. Let us formalize it by determining the additional demand volume initiated by it $\left(C_{d}^{1}\right)$ :

$$
C_{d}^{1}=I N_{1}+I N_{1} \times\left(1-M_{\text {out }}\right)+I N_{1} \times\left(1-M_{\text {out }}\right)^{2}+\cdots+I N_{1} \times\left(1-M_{\text {out }}\right)^{n}
$$

where $M_{\text {out }}$ is the marginal value of outward flows from the multiplier process $\left(0 \leqslant M_{\text {out }} \leqslant 1\right)$. Each summand of Equation 9 , except the first, describes spending the income received by the next group of process participants from the previous group of process participants, considering the sums of outward flows. It is these expenditures that spread the multiplier effect along the chain of the process participants. In turn, $M_{\text {out }}$ is composed of the following components:

$$
M_{\text {out }}=M_{t}+M_{i}+M_{S}
$$

where $M_{t}$ is the value of the marginal tax payment rate, $M_{i}$ is the value of the marginal propensity to import from outside the region, $M_{s}$ is marginal propensity to save in the analyzed economy.

If each summand of Equation 9 described the demand of a single resource supplier, the values of $M_{\text {out }}$ would change at each stage of the analyzed process - from supplier to supplier. However, each summand of Equation 9 describes the demand of a sufficiently broad group of resource suppliers for each previous sufficiently broad group of buyers. It is a kind of mini-economy consisting of a large-scale set of participants. This extremely large-scale set at each stage of the process described by Equation 9 allows us to approach the economy of each stage in the same way as a higher-order economy. Demand at each stage of the described process is dispersed through a large-scale prism of consumers, leveling particular individuals' preferences and, due to this dispersion with extremely low weights of its participants, forming the total marginal value of outward flows from the income received by a wide group of individuals, the same for each process stage described by Formula 9 and the formulas below. At the same time, for the periods of economic growth and economic crisis, the values of $M_{\text {out }}$ will be different, which will lead to the calculation of individual values of the multiplier for the period of growth and the period of crisis, respectively.

The value of exports is not reflected in the Equation 10 because, like investment and government spending, exports are the impulse that generates multiplier chains rather than a component of the multiplier coefficient. Just as saving is an outward flow from the consumption process, imports are an outward flow from the formation of net exports. Consequently, consumption and exports generate multiplier chains' impulses, while saving and imports are reflected in the value of outward flows $\left(M_{\text {out }}\right)$.

Simplifying Equation 9, we get a simple formula for the IM- see Equation 8:

$$
C_{d}^{1}=\lim _{n \rightarrow \infty} \sum_{i=0}^{n} I N_{1} \times\left(1-M_{\text {out }}\right)^{i}=I N_{1} \times \frac{1}{M_{\text {out }}}
$$

where $n$ is the number of components of the multiplier process, $i$ is the number of the multiplier process component.

The additional demand of $\mathrm{C}_{d}^{1}$ volume needs to be satisfied, which requires additional investment in production capacity. The value of the investment accelerator $A(0 \leqslant A \leqslant 1)$ shows the amount of investment needed per unit of additional demand. The amount of additional investment generated by the accelerator $\left(I N_{d}^{1}\right)$ will be: 


$$
I N_{d}^{1}=I N_{1} \times\left(1-M_{\text {out }}\right) \times A+I N_{1} \times\left(1-M_{\text {out }}\right)^{2} \times A+\cdots+I N_{1} \times\left(1-M_{\text {out }}\right)^{n} \times A
$$

or:

$$
I N_{d}^{1}=C_{d}^{1} \times\left(1-M_{\text {out }}\right) \times \mathrm{A}=I N_{1} \times \frac{\left(1-M_{\text {out }}\right) \times A}{M_{\text {out }}}
$$

Equation 12 is derived from Equation 9 by multiplying all its summands except the first by the investment value. The first summand $\left(\mathrm{IN}_{1}\right)$ is excluded as an investment. The value of $\mathrm{A}$ for each summand (next stage) in Equation 12 is not the value of each next branch accelerator. If it were so, the value of A would change from stage to stage. However, at each stage, there is a scattering of demand. The masses of stage participants buy a wide range of products for both personal and corporate use. As a result, there is demand dispersion among a wide range of industries, leading to the formation of their low individual weights and low weights of their accelerators, averaging A value to its invariable values at each stage in Equation 12 and the formulas below.

In this case, if the vast majority of industries from this broad spectrum are loaded, A's value will be high, and if they are idle, it will be low. Similarly, creating a wide range of additional capacity beyond the region's borders will allow additional demand to be met without creating additional production capacity within the region's borders, which will result in low values of the regional accelerator.

Each component of Equation 12, being investments, triggers its component of the second part of the multiplier process, described by Equation 9 . The total additional volume of the demand formed by them $\left(C_{d}^{2}\right)$ is calculated by the formula:

$$
C_{d}^{2}=\frac{I N_{d}^{1}}{M_{\text {out }}}=I N_{1} \times \frac{\left(1-M_{\text {out }}\right) \times A}{M_{\text {out }}} \times \frac{1}{M_{\text {out }}}=I N_{1} \times \frac{\left(1-M_{\text {out }}\right) \times A}{M_{\text {out }}{ }^{2}}
$$

The amount of investment needed to meet this volume of demand is determined by the Equation 15 :

$$
I N_{d}^{2}=C_{d}^{2} \times\left(1-M_{\text {out }}\right) \times \mathrm{A}=I N_{1} \times\left[\frac{\left(1-M_{\text {out }}\right) \times A}{M_{\text {out }}}\right]^{2}
$$

Analysis of Equations 9 to 15 allows us to conclude that the process of interaction of multiplier and investment accelerator consists of the same elements, which combination is repeated at different scales (self-similar). Based on the self-similarity, we calculate the total values of demand $\left(\mathrm{T}_{\mathrm{d}}\right)$ and investment $\left(\mathrm{T}_{\mathrm{i}}\right)$ generated by the interaction of multiplier and investment accelerator:

$$
T_{d}=\frac{I N_{1}}{M_{\text {out }}}+\frac{I N_{1}}{M_{\text {out }}} \times \frac{\left(1-M_{\text {out }}\right) \times A}{M_{\text {out }}}+\frac{I N_{1}}{M_{\text {out }}} \times\left[\frac{\left(1-M_{\text {out }}\right) \times A}{M_{\text {out }}}\right]^{2}+\cdots+\frac{I N_{1}}{M_{\text {out }}} \times\left[\frac{\left(1-M_{\text {out }}\right) \times A}{M_{\text {out }}}\right]^{n}
$$

or:

$$
T_{d}=\lim _{n \rightarrow \infty} \sum_{i=0}^{n} \frac{I N_{1}}{M_{\text {out }}} \times\left[\frac{\left(1-M_{\text {out }}\right) \times A}{M_{\text {out }}}\right]^{i}=I N_{1} \times \frac{1}{\left(1-\frac{\left(1-M_{\text {out }}\right) \times A}{M_{\text {out }}}\right) \times M_{\text {out }}}
$$

where;

$$
M U L T=\frac{1}{\left(1-\frac{\left(1-M_{\text {out }}\right) \times A}{M_{\text {out }}}\right) \times M_{\text {out }}}
$$

where $M U L T$ is the coefficient of the IM interacting with the accelerator. Similarly:

$$
T_{i}=I N_{1}+I N_{1} \times \frac{\left(1-M_{\text {out }}\right) \times A}{M_{\text {out }}}+I N_{1} \times\left[\frac{\left(1-M_{\text {out }}\right) \times A}{M_{\text {out }}}\right]^{2}+\cdots+I N_{1} \times\left[\frac{\left(1-M_{\text {out }}\right) \times A}{M_{\text {out }}}\right]^{n}
$$

or:

$$
T_{i}=\lim _{n \rightarrow \infty} \sum_{i=0}^{n} I N_{1} \times\left[\frac{\left(1-M_{\text {out }}\right) \times A}{M_{\text {out }}}\right]^{i}=I N_{1} \times \frac{1}{\left(1-\frac{\left(1-M_{\text {out }}\right) \times A}{M_{\text {out }}}\right)}
$$

where;

$$
A C C E L=\frac{1}{\left(1-\frac{\left(1-M_{\text {out }}\right) \times A}{M_{\text {out }}}\right)}
$$

where $A C C E L$ is investment accelerator coefficient, taking into account the multiplier effect. Since $T_{d} \frac{=T_{i}}{M_{o u t}}$, it may be easier to obtain the value of $T_{i}$ :

$$
T_{i}=T_{d} \times M_{\text {out }}=I N_{1} \times \frac{1}{\left(1-\frac{\left(1-M_{\text {out }}\right) \times A}{M_{\text {out }}}\right) \times M_{\text {out }}} \times M_{\text {out }}=I N_{1} \times \frac{1}{\left(1-\frac{\left(1-M_{\text {out }}\right) \times A}{M_{\text {out }}}\right)}
$$


Equation 17 is used to estimate the total increase in demand caused by investments in the development of the regional economy with the volume of $I N_{l}$. Equation 20 is used to estimate the necessary volume of investments (including $I N_{l}$ ) in the regional economy to meet multiplicatively growing demand.

The coefficient values that characterize the values of outward flows from the multiplier process and Equation 10, as well as the value of investment accelerator, can be obtained from regression models of the form:

$y=b \times G R P$

where $b$ is regression coefficient, $G R P$ is gross regional product value. The correspondence of the indicator values $y$ and $b$ is shown in Table 1 .

Table 1. Correspondence of the indicator values $y$ and $b$ in Equation 23

\begin{tabular}{|c|c|}
\hline $\mathbf{y}$ & $\mathbf{b}$ \\
\hline $\begin{array}{l}\text { The volume of tax revenues to the budget system of the Russian Federation } \\
\text { from the region's economy }\end{array}$ & Marginal rate of tax payments \\
\hline The volume of imports into the regional economy & Marginal propensity to import \\
\hline The volume of export from the region's economy & Marginal propensity to export \\
\hline Investment volume in fixed capital of the region's economy & Investment accelerator value \\
\hline
\end{tabular}

Having thus determined the volume of regional exports $\left(E X P_{r e g}\right)$, the volume of imports into the regional economy $\left(I M P_{r e g}\right)$ is determined based on the formula for calculating the value of the gross regional product (GRP):

$$
G R P=C_{r e g}+I_{r e g}+G_{r e g}+E X P_{r e g}-I M P_{r e g}
$$

where $C_{r e g}$ is the amount of consumer spending in the regional economy, $I_{\text {reg }}$ is the amount of gross private domestic investment in the regional economy, and $G_{r e g}$ is the amount of government spending in the region's economy. Let us denote:

$$
T_{c}=C_{\text {reg }}+I_{\text {reg }}+G_{\text {reg }}
$$

where $T_{c}$ is the total volume of consumption in the economy of the region in the analyzed period.

Then Equation 24 takes the form:

$$
G R P=T_{c}+E X P_{r e g}-I M P_{r e g}
$$

from which:

$$
I M P_{\text {reg }}=T_{c}-\left(G R P r e g-E X P_{\text {reg }}\right)
$$

where $\left(G R P_{r e g}-E X P_{r e g}\right)$ is the volume of own production consumed in the region's economy for the analyzed period.

The difference between the total volume of products consumed in the regional economy and the volume of products of own production consumed over the same period will provide the value of imports into the regional economy. The calculation of IM values was made for Kurgan, Sverdlovsk, and Chelyabinsk regions. These regions were selected because they have a strong industrial potential, given that the economy of Russia requires the transfer to the rails of knowledge-intensive industrial development. Thus, in 2021, in order to analyze the implementation of regional industrial policy and determine the effectiveness of the state support tools, the Ministry of Industry and Trade of the Russian Federation tested a pilot project for rating the 20 most effective industrial regions, which included Kurgan, Sverdlovsk, and Chelyabinsk regions [31].

\section{4- Results}

Using Equations 18 and 23, we calculate the IM values for Kurgan, Sverdlovsk, and Chelyabinsk regions' economies. The volume of initial quarterly information for calculations (for 2005-2019) is quite large, so they are presented selectively in annual terms in Table 2. 
Table 2. Input data (selectively) to calculate the values of IMs of Kurgan, Sverdlovsk, and Chelyabinsk regions [32]

\begin{tabular}{|c|c|c|c|c|c|c|c|c|c|c|}
\hline Indicator & 2005 & 2007 & 2009 & 2010 & 2013 & 2015 & 2016 & 2017 & 2018 & 2019 \\
\hline \multicolumn{11}{|c|}{ Kurgan region } \\
\hline Population, thousand people & 961.8 & 934.5 & 918.6 & 908.8 & 877.1 & 861.9 & 854.1 & 845.5 & 834.7 & 827.2 \\
\hline GRP, mln. RUB & 50246 & 81076 & 107915 & 117880 & 167038 & 179436 & 189790 & 200868 & 213032 & 233469 \\
\hline Investment in fixed capital, mln. RUB & 8628 & 19043 & 35021 & 25573 & 33207 & 27842 & 29254 & 22851 & 27151 & 40238 \\
\hline Consumer spending per capita (per month), RUB & 3263 & 6119.5 & 8141.1 & 8646 & 12920 & 14740 & 14834 & 15581 & 16133 & 17075 \\
\hline $\begin{array}{l}\text { Taxes (compulsory payments) to the budget system } \\
\text { of the Russian Federation, mln. RUB }\end{array}$ & 6946 & 11636 & 12047 & 15068 & 19692 & 22105 & 26127 & 28403 & 27089 & 30963 \\
\hline \multicolumn{11}{|c|}{ Sverdlovsk region } \\
\hline Population, thousand people & 4356.4 & 4320.1 & 4308.5 & 4297.3 & 4320.7 & 4330 & 4329.4 & 4325.3 & 4315.7 & 4310.7 \\
\hline GRP, mln. RUB & 475576 & 820793 & 825267 & 1046600 & 1568655 & 1822835 & 1990837 & 2142514 & 2277576 & 2529549 \\
\hline Investment in fixed capital, mln. RUB & 91019 & 187314 & 200368 & 264462 & 352916 & 349964 & 328403 & 320111 & 378662 & 450397 \\
\hline Consumer spending per capita (per month), RUB & 6055 & 10245.5 & 14291.4 & 16694 & 25823 & 28403 & 28869 & 29954 & 31757 & 33457 \\
\hline $\begin{array}{l}\text { Taxes (compulsory payments) to the budget system } \\
\text { of the Russian Federation, mln. RUB }\end{array}$ & 90853 & 149340 & 119167 & 161248 & 217592 & 244504 & 269964 & 312412 & 358884 & 381067 \\
\hline \multicolumn{11}{|c|}{ Chelyabinsk region } \\
\hline Population, thousand people & 3516.7 & 3489.1 & 3481.8 & 3475.6 & 3490.1 & 3500.7 & 3502.3 & 3493 & 3475.7 & 3466.3 \\
\hline GRP, mln. RUB & 349957 & 575644 & 556985 & 652865 & 882340 & 1209243 & 1271133 & 1348565 & 1473728 & 1545583 \\
\hline Investment in fixed capital, mln. RUB & 72848 & 130926 & 145446 & 151121 & 214964 & 217238 & 198289 & 198991 & 254993 & 299051 \\
\hline Consumer spending per capita (per month), RUB & 4571 & 7795.6 & 10551 & 11390 & 17906 & 17700 & 17274 & 17339 & 18237 & 19500 \\
\hline $\begin{array}{l}\text { Taxes (compulsory payments) to the budget system } \\
\text { of the Russian Federation, mln. RUB }\end{array}$ & 53292 & 96767 & 58052 & 93419 & 132790 & 179604 & 193994 & 214070 & 240066 & 244974 \\
\hline
\end{tabular}

Based on these data, the components of the Equation 10 were determined. The values of the components were determined by statistical methods of regression analysis, namely, by linear regression with one regression model building of the Equation 23. In Equation 23, there is no free term (a). In preliminary modeling, the dependence of autonomous consumption in the economies of Kurgan, Sverdlovsk, and Chelyabinsk regions on crediting was revealed weakly related to the amount of income.

When using the IM as a tool for managing the region's economy, it is necessary to rely on the real multiplier effects, based on the activity of investors, developing the region's economy. The emphasis on generating effects at the expense of crediting consumer demand is possible for supporting economic growth, but not in the current conditions of the modern Russian economy when the debt load of the population in the summer of 2020 reached a historical maximum, and every fourth borrower (23\%) is forced to give the banks more than $80 \%$ of their income, while the real disposable income of Russians in the second quarter of 2020 fell by $8 \%$ [33]. In such circumstances, the generation of multiplier effects by stimulating consumer crediting generates additional risks for the banking system and the economy as a whole (in May 2020, the volume of overdue credits increased by 25 billion rubles or 3\%). Instead of multiplier growth, such an approach can turn into a large-scale financial crisis.

As part of the multiplier application as a tool of regional economy management and considering the above, this paper relies on the multiplier effects, not based on the increase in consumer credit, which substantiates the selected form of Equation 23. Based on this equation and the data in Table 2, three regression equations (nine equations in total) are generated for each region's economy. The volumes of regional exports and imports were not determined due to the above-described lack of the required data in the public domain. The generated regression models have the following form for the Sverdlovsk region's economy:

$$
\begin{aligned}
& C_{\text {reg }}=\left(1-M_{s}\right) \times G R P=(1-0.2192) \times G R P \\
& T_{\text {reg }}=M_{t} \times G R P=0.1453 \times G R P \\
& I_{\text {reg }}=A \times G R P=0.2027 \times G R P
\end{aligned}
$$

where $C_{\text {reg }}$ is the amount of consumer spending in the regional economy, $T_{\text {reg }}$ is the volume of taxes, fees, and other compulsory payments to the budget system of the Russian Federation from the region's economy (the volume of tax revenues from the region's economy to the federal budget, the budget of the region, and the budgets of the territories administratively included in it), $I_{\text {reg }}$ is the volume of investment in fixed capital in the regional economy, $M_{S}=$ $d S_{\text {reg }} / d G R P$ is the value of the marginal propensity to save $(0.2192$ for the economy of the Sverdlovsk region $), M_{t}=$ $d T_{\text {reg }} / d G R P$ is the value of the marginal rate of tax payments ( 0.1453 for the economy of the Sverdlovsk region $), A=$ 
$d I_{\text {reg }} / d G R P$ is the value of investment accelerator ( 0.2027 for the economy of the Sverdlovsk region), and $S_{\text {reg }}$ is the amount of savings in the regional economy.

For the economy of the Kurgan region

$$
\begin{aligned}
& C_{r e g}=\left(1-M_{s}\right) \times G R P=(1-0.1875) \times G R P \\
& T_{r e g}=M_{t} \times G R P=0.1303 \times G R P \\
& I_{r e g}=A \times G R P=0,191 \times G R P
\end{aligned}
$$

For the economy of the Chelyabinsk region:

$$
\begin{aligned}
& C_{\text {reg }}=\left(1-M_{s}\right) \times G R P=(1-0.349) \times G R P \\
& T_{\text {reg }}=M_{t} \times G R P=0.1515 \times G R P \\
& I_{\text {reg }}=A \times G R P=0.1978 \times G R P
\end{aligned}
$$

Obtained estimates of statistical significance of regression Equations 28 to 36 are shown in Table 3.

Table 3. Estimates of statistical significance of regression equations for the economies of Kurgan, Sverdlovsk, and Chelyabinsk regions

\begin{tabular}{ccccccccc}
\hline \multirow{2}{*}{ Region } & Coeff. b & b value & \multicolumn{7}{c}{ Significance of regression equations } \\
\cline { 4 - 9 } & & & R-squared & Norm. R-squared & Significance $\mathbf{F}$ & Standard error & t-statistics & P-value \\
\hline \multirow{3}{*}{ Kurgan region } & $1-M_{S}$ & $1-0.1875$ & 0.9986 & 0.9153 & $2.51 \mathrm{E}-17$ & 0.0087 & 93.847 & $1.43 \mathrm{E}-18$ \\
& $M_{T}$ & 0.1303 & 0.9957 & 0.9124 & $1.35 \mathrm{E}-14$ & 0.0025 & 52.936 & $1.36 \mathrm{E}-15$ \\
& $A$ & 0.191 & 0.9192 & 0.8359 & $1.53 \mathrm{E}-07$ & 0.0163 & 11.686 & $6.49 \mathrm{E}-08$ \\
\hline \multirow{5}{*}{ Sverdlovsk region } & $1-M_{S}$ & $1-0.2192$ & 0.9946 & 0.9113 & $4.86 \mathrm{E}-14$ & 0.0166 & 47.085 & $5.51 \mathrm{E}-15$ \\
& $M_{T}$ & 0.1453 & 0.9912 & 0.9079 & $7.21 \mathrm{E}-13$ & 0.0039 & 36.791 & $1.04 \mathrm{E}-13$ \\
& $A$ & 0.2027 & 0.9655 & 0.8821 & $1.37 \mathrm{E}-09$ & 0.0111 & 18.319 & $3.88 \mathrm{E}-10$ \\
\hline \multirow{3}{*}{ Chelyabinsk region } & $1-M_{S}$ & $1-0.349$ & 0.9765 & 0.8931 & $1.64 \mathrm{E}-10$ & 0.0292 & 22.316 & $3.87 \mathrm{E}-11$ \\
& $M_{T}$ & 0.1515 & 0.9957 & 0.9124 & $1.39 \mathrm{E}-14$ & 0.0029 & 52.782 & $1.41 \mathrm{E}-15$ \\
& $A$ & 0.1978 & 0.9594 & 0.876 & $3.36 \mathrm{E}-09$ & 0.0117 & 16.835 & $1.03 \mathrm{E}-09$ \\
\hline
\end{tabular}

Based on the obtained values of the coefficients $b$ and Equation 18, we calculated the values of IMs for the three analyzed areas (Table 4).

Table 4. IMs of the economies of Kurgan, Sverdlovsk, and Chelyabinsk regions

\begin{tabular}{cc}
\hline Region & The IM value \\
\hline Kurgan region & 5.33398 \\
Sverdlovsk region & 4.24298 \\
Chelyabinsk region & 2.48939 \\
\hline
\end{tabular}

The lowest value of the IM is observed in the economy of the Chelyabinsk region, while the volume of GRP per capita in the Kurgan region (which has the highest value of the multiplier) is lower than in the Chelyabinsk and Sverdlovsk regions. The reason is the differences in the structures of the analyzed economies. In order to determine them, let us consider regional differences in the structure of the volume of shipped goods, performed works, and services (Table 5 - averaged data of 2005-2019).

Table 5. Regional differences in the structure of the volume of shipped goods, work, and services [32]

\begin{tabular}{cccc}
\hline Products & \multicolumn{3}{c}{ Region } \\
\cline { 2 - 4 } & Kurgan \% & Sverdlovsk \% & Chelyabinsk \% \\
\hline Food, beverages, tobacco, leather, and leather goods & 20.35 & 6.58 & 9.72 \\
Products of the wood, paper, printing industry & 1.27 & 0.99 & 0.44 \\
Coke, petroleum products, non-metallic mineral products, chemical products & 12.64 & 9.75 & 11.16 \\
Metallurgy, metal goods & 19.53 & 58.08 & 60.26 \\
Machinery, equipment, electronic and optical products, electrical equipment & 32.49 & 14.88 & 12.37 \\
Other manufacturing industries & 13.72 & 9.72 & 6.05 \\
\hline Total & 100 & 100 & 100 \\
\hline
\end{tabular}


Analyzing Table 5, we can conclude that machines, electronic and optical products, and electrical equipment prevail in the Kurgan region's economic production structure. In other words, the share of complex industrial production is rather high $(32.49 \%)$, which generates large-scale multiplier effects, becoming the reason for the high value of the Kurgan region's IM. It should be noted that the economy of the Kurgan region is well-balanced. So, apart from the production of complex industrial products, the share of food, beverages, tobacco products, leather and leather goods $(20.35 \%)$, metallurgy, metal products $(19.53 \%)$, coke, oil products, chemical products $(12.64 \%)$ is high.

The Sverdlovsk Region's economy, which has a lower value of the IM, is dominated by less complex metallurgy and metal goods production (58.08\%). The share of complex machines and equipment production is almost half (14.88\%) of the similar indicator of the Kurgan region economy.

The dependence of the Chelyabinsk region's economy on the production of simple industrial products (metallurgy, metal products) is even higher. The average share of these products in the region's economy is $60.26 \%$. At the same time, the share of production of complex industrial products is the lowest among the analyzed regions $-12.37 \%$, which determines a lower value of the IM for this region.

Significant importance can be derived from how regional differences in the volume of shipped goods, work, and services influence IM. If we compare product differentiation, we can establish that the biggest influence is provided by machinery, equipment, electronic and optical products, electrical equipment. If we look at the results from forming the most effective investment policy, we must point to the connection of technologically and productively complex products and an investment multiplier. In simple words, the higher the product is in the production chain, the higher the multiplicative effect it has on all downstream processes.

From the position of the macroeconomic policy of the state, the results obtained indicate a direct relationship between the regionally dominant industry and its effect on production-related entities, which in turn allows us to talk about the need to further scale the results from the region to the level of federal districts.

\section{5- Discussion}

To summarize, we note that this study could achieve the objectives and obtain the following results with investment areas:

- A review of existing approaches in domestic and foreign studies to calculating the IM was conducted, which allowed us to identify existing problems in this subject area. The study results also confirmed the auxiliary hypotheses that the IM is the action enhancer of public and private investors on the country's economy development and that the values of multipliers of Russia's particular industries and regions are different (which was demonstrated on the example of Kurgan, Sverdlovsk, and Chelyabinsk regions).

- An approach to estimating the IM considering the difference and peculiarities of the investment potential level of the analyzed regions of Russia has been proposed. It was noted that the differences in the structures of the analyzed regional economies are one of the reasons for different values of the multiplier. The lowest value of the IM is observed in the economy of the Chelyabinsk region, although the GRP per capita in the Kurgan region having the highest value of the multiplier is lower than in the Chelyabinsk and Sverdlovsk regions.

- The main directions of economic development of the regions under consideration using the potential of the multiplier effect are defined. For the economies of the Sverdlovsk and Chelyabinsk regions, it is proposed to bring their industrial potential to a higher level, namely by:

- Investments in increasing the share of knowledge-intensive, modern production of complex engineering products will make it possible to use the existing industrial base in the economies of these regions to increase the multiplier effect and will provide a basis for increasing the share of added value formed by science and education;

○ Investments in chemical production.

These investment areas will increase the industry multiplier value, making it the growth point of the economies of the analyzed regions.

Many domestic and foreign researchers use the input-output model to study various negative and positive multiplier effects, calculating the values of sectoral multipliers for the Russian economy to model the multiplier effects. Through literature analysis, we can establish a significant research gap in macroeconomic understanding of how investment multiplier can be used as a regional development tool. The scientific novelty of the results obtained consists of developing a methodology that allows us to apply changes in the dynamics of regional multiplier processes as a basis for determining the key points of regional economies' development. 
For the economy of the Kurgan region and the economies of the Sverdlovsk and Chelyabinsk regions, the first growth driver is the further development of sophisticated machine-building industries. In the Kurgan region, the second, no less powerful in forming the multiplier effect of the region's development is the production of food based on agriculture. The simultaneous development of the processing industry and agriculture will allow the economy of the Kurgan region to generate more large-scale multiplier effects, creating new points of growth. A greater specification of the key points of investment application in the economy of the analyzed regions is possible after calculating sectoral values of IMs for each of them using the methodology presented above.

Thus, a high share of complex industrial production and the balanced development of the economy are the factors determining the high value of the regional IM determining the main development directions of regional economies for obtaining a larger multiplier effect, increasing the effectiveness of efforts on this development.

The proposed application of the IM as an economic development tool is possible at the levels of particular regions and the country by studying the impact of the values of regional multipliers and the overall structure of the economy on the IM value for the country. Targeted regional and sectoral funding aimed at increasing some and reducing other multiplier chains will make it possible to manage the value of the Russian IM and, through its management, manage the economic development rate of the Russian Federation. A similar experience can be implemented at the level of other states. In addition, the proposed model can be used in assessing the indirect effects of large investment projects arising from the multiplicative transfer of the impact part of these projects to adjacent industries and regions.

\section{6- Conclusion}

The presented methodology is proposed to calculate the values of the region's multipliers and particular industries within the region's economy. The values of multipliers for different industries and the generalized multiplier value for the region's economy will differ from each other because of the different values of Mout in different industries and because when calculating the total regional multiplier (as in the case of the IM in the country's economy), industry emphasis is not necessary and is impossible because the multiplier effect on the economy is considered. Thus, the presented methodology makes it possible, for example, to obtain the IM value for the economy of the Kurgan region, the machine-building sector of this region, the construction sector of this region, etc. The values of the industry multipliers in the region impact the value of the regional multiplier. The study revealed the current lack of official Russian statistical data for calculating the values of industry multipliers within the economy of a particular region. Therefore, within this article, the general regional values of the multiplier are calculated based on the proposed methodology. The proposed methodology can be used in developing strategic planning documents at the regional level, forecasts, and programs for the socio-economic development of the regions. It can also be used to make informed managerial decisions on the development of individual sectors of the economy of the Russian regions. The novelty of this work allows us to identify the main directions of development of the analyzed regions' economies using the potential of the multiplier effect. The results obtained allowed us to achieve the objective set at the beginning of the study and confirm the correctness of the hypothesis that the IM effect can be used as a tool to identify key points of economic growth in Russia's regions and improve the quality and effectiveness of managerial decisions at the regional level. The practical significance of this study is that it offers an analytical tool identifying key points of regional economic development and managing the IM value to create new points, investments in which will entail a large-scale multiplier effect in developing the regional economy.

The study limitations were the lack of data in regional statistics; the problems were the high level of uncertainty in developing and implementing new technological solutions (to which the multiplier belongs). In the future, it is planned to expand the proposed IM model by integrating the models into it, reflecting the dependence of economic growth rates on the time of creating and launching production facilities and the relationship of regional exports and imports with the dissemination stages of multiplier effects in the regional economy.

\section{7- Declarations}

\section{7-1- Author Contributions}

Conceptualization, M.E.K. and V.V.E.; methodology, V.V.E.; software, T.S.O.G.; validation, V.V.E., S.A.P., and T.S.O.G.; formal analysis, V.V.E.; investigation, M.E.K.; resources, M.E.K.; data curation, S.A.P.; writing-original draft preparation, V.V.E.; writing-review and editing, M.E.K.; visualization, T.S.O.G.; supervision, M.E.K.; project administration, M.E.K. All authors have read and agreed to the published version of the manuscript.

\section{7-2- Data Availability Statement}

Publicly available datasets were analyzed in this study. This data can be found here: [https://minpromtorg.gov.ru/en/] and [https://eng.rosstat.gov.ru/]. 


\section{7-3- Funding}

The authors received no financial support for the research, authorship, and/or publication of this article.

\section{7-5- Conflicts of Interest}

The authors declare that there is no conflict of interests regarding the publication of this manuscript. In addition, the ethical issues, including plagiarism, informed consent, misconduct, data fabrication and/or falsification, double publication and/or submission, and redundancies have been completely observed by the authors.

\section{8- References}

[1] Collingro, F., \& Frenkel, M. (2020). Fiscal multipliers in the euro area: A comparative study. The Quarterly Review of Economics and Finance. doi:10.1016/j.qref.2020.08.005.

[2] Oosterhaven J., Hewings G.J.D. (2021) Interregional Input-Output Models. In: Fischer M.M., Nijkamp P. (eds.) Handbook of Regional Science, 875-901. Springer, Berlin, Heidelberg. doi:10.1007/978-3-662-60723-7_43.

[3] Ponomarev, Ju. Ju., and Evdokimov, D. Ju. (2020). Estimation of extended multiplicative socio-economic effects based on the input-output balance model”. Economic development of Russia 27 (7), 30-45. (In Russian).

[4] Ministry of Finance of the Russian Federation. (2020). Data on the execution of consolidated budgets of the subjects of the Russian Federation at January 1, 2020. Available online: https://minfin.gov.ru/ru/document/?id_4=129623dannye_b_ispolnenii _konsolidirovannykh_byudzhetov_subektov_rossiiskoi_federatsii_na_1_yanvarya_2020_goda (accessed April 2021).

[5] Giambattista, E., \& Pennings, S. (2017). When is the government transfer multiplier large? European Economic Review, 100, 525-543. doi:10.1016/j.euroecorev.2017.09.003.

[6] Ksenofontov, M. Y., Shirov, A. A., Polzikov, D. A., \& Yantovskii, A. A. (2018). Assessing Multiplier Effects in the Russian Economy: Input-Output Approach. Studies on Russian Economic Development, 29(2), 109-115. doi:10.1134/S1075700718020089.

[7] Bayer, C., Born, B., Luetticke, R., \& Müller, G. J. (2020). The Coronavirus Stimulus Package: How Large is the Transfer Multiplier? CEPR Discussion Paper No. DP14600, Available online: https://ssrn.com/abstract=3594222 (accessed April 2021).

[8] Izquierdo, A., Lama, R., Medina, J., Puig, J., Riera-Crichton, D., Vegh, C., \& Vuletin, G. J. (2019). Is the Public Investment Multiplier Higher in Developing Countries? An Empirical Exploration. IMF Working Papers, 19(289), 1-48. doi:10.5089/9781513521114.001.

[9] Miller, R. E., \& Blair, P. D. (2009). Input-output analysis: Foundations and extensions, second edition. In Input-Output Analysis: Foundations and Extensions, Second Edition (2nd ed), 1-750. doi:10.1017/CBO9780511626982.

[10] Evstratov, A. A., Kalinin, A. M., \& Parsegov, S. G. (2016). The use of input-output tables to forecast the effects of demand stimulation state policy. Studies on Russian Economic Development, 27(1), 13-20. doi:10.1134/S1075700716010032.

[11] Wilson, D. J. (2020). The covid-19 fiscal multiplier: Lessons from the great recession. FRBSF Economic Letter, 13, 1-5.

[12] Suvorov, P. A. (2014). Cost-Release Method as a Tool for Evaluating the Macroeconomic Efficiency of Innovation and Investment Projects. Extended abstract of PhD dissertation (Economics), Moscow, (In Russian).

[13] Boehm, C. E. (2020). Government consumption and investment: Does the composition of purchases affect the multiplier? Journal of Monetary Economics, 115, 80-93. doi:10.1016/j.jmoneco.2019.05.003.

[14] Chodorow-Reich, G. (2019). Geographic cross-sectional fiscal spending multipliers: What have we learned? American Economic Journal: Microeconomics, 11(2), 1-34. doi:10.1257/pol.20160465.

[15] Goridko, N. P., \& Nizhegorodtsev, R. M. (2018). The growth points of regional economy and regression estimation for branch investment multipliers. Economy of Region, 14(1), 29-42. doi:10.17059/2018-1-3.

[16] Silvestrov, S. N., Bauer, V. P., \& Eremin, V. V. (2018). Estimation of the dependence of the investment multiplier on the structure of the regional economy. Economy of Region, 14(4), 1463-1476. doi:10.17059/2018-4-31.

[17] Zyablitskiy, I. (2020). Estimating fiscal multipliers in Russian economy. HSE Economic Journal, 24(2), $268-294$. doi:10.17323/1813-8691-2020-24-2-268-294.

[18] Ganelli, G., \& Tervala, J. (2020). Welfare Multiplier of Public Investment. IMF Economic Review, 68(2), 390-420. doi:10.1057/s41308-020-00111-7.

[19] Idrisov, G. I., \& Ponomarev, Y. Y. (2019). Infrastructure mortgage in Russia: Opportunities and prospects. Voprosy Ekonomiki, 2(2), 114-133. doi:10.32609/0042-8736-2019-2-114-133.

[20] Leonidova, E. G., \& Sidorov, M. A. (2019). Structural changes in the economy: searching for sectoral drivers of growth. Economic and social changes: facts, trends, forecast, 12(6), 166-181. doi.org/10.15838/esc.2019.6.66.9.

[21] Ramey, V. A., \& Zubairy, S. (2018). Government spending multipliers in good times and in bad: Evidence from US historical data. Journal of Political Economy, 126(2), 850-901. doi:10.1086/696277.

[22] Deleidi, M., Iafrate, F., \& Levrero, E. S. (2020). Public investment fiscal multipliers: An empirical assessment for European countries. Structural Change and Economic Dynamics, 52, 354-365. doi:10.1016/j.strueco.2019.12.004. 
[23] Kameda, T., Namba, R., \& Tsuruga, T. (2021). Decomposing local fiscal multipliers: Evidence from Japan. Japan and the World Economy, 57. doi:10.1016/j.japwor.2021.101053.

[24] Czubak, W., Pawłowski, K. P., \& Sadowski, A. (2021). Outcomes of farm investment in Central and Eastern Europe: The role of financial public support and investment scale. Land Use Policy, 108, 105655. doi:10.1016/j.landusepol.2021.105655.

[25] Debuque-Gonzales, M. (2021). Local fiscal multipliers and spillover effects: Evidence from Philippine regions. Economic Systems, 45(2), 100764. doi:10.1016/j.ecosys.2020.100764.

[26] Derkacz, A. J. (2020). Fiscal, investment and export multipliers and the COVID-19 pandemic slowdowns uncertainty factor in the first half of 2020. Risks, 8(4), 1-21. doi:10.3390/risks8040122.

[27] Boehm, C. E. (2020). Government consumption and investment: Does the composition of purchases affect the multiplier? Journal of Monetary Economics, 115, 80-93. doi:10.1016/j.jmoneco.2019.05.003.

[28] Ganelli, G., \& Tervala, J. (2020). Welfare Multiplier of Public Investment. IMF Economic Review, 68(2), 390-420. doi:10.1057/s41308-020-00111-7.

[29] Goridko, N. P., \& Nizhegorodtsev, R. M. (2018). The growth points of regional economy and regression estimation for branch investment multipliers. Economy of Region, 14(1), 29-42. doi:10.17059/2018-1-3.

[30] Silvestrov, S. N., Bauer, V. P., \& Eremin, V. V. (2018). Estimation of the dependence of the investment multiplier on the structure of the regional economy. Economy of Region, 14(4), 1463-1476. doi:10.17059/2018-4-31.

[31] Ministry of Industry and Trade of Russia. (2021). Ministry of Industry and Trade of the Russia presented top 20 regions with effective implementation of industrial policy. Moscow, Russia. Available online: https://minpromtorg.gov.ru/presscentre/news/\#!minpromtorg_rossii_prezentoval_top20_regionov_s_effektivnoy_realizaciey_promyshlennoy_politiki (accessed April 2021).

[32] Federal State Statistics Service. (2021). Regions of Russia. Main characteristics of the subjects of the Russian Federation" Moscow, Russia. Available online: https://gks.ru/folder/210/document/13205 (accessed March 2021).

[33] Finanz Portal. (2021). Debt load of Russian people achieved a new record. Moscow, Russia. Available online: https://www.finanz.ru/novosti/lichnyye-finansy/dolgovaya-nagruzka-rossiyan-dostigla-novogo-rekorda-1029295868 (accessed June 2021). 